\title{
Nonlinear Properties of Chalcogenide Glass Fibers
}

\author{
Jas S. Sanghera, L. Brandon Shaw, \\ C. M. Florea, P. Pureza, V. Q. Nguyen, \\ F. Kung, Dan Gibson and I. D. Aggarwal \\ Naval Research Laboratory \\ USA
}

\section{Introduction}

Chalcogenide glasses are based on the chalcogen elements S, Se and Te with the addition of other elements such as $\mathrm{Ge}$, As and $\mathrm{Sb}$ to form of stable glasses (Borisova, 1981). Due to their large IR transparency, fibers fabricated from these glasses are ideal for transmission of high power IR light. Several applications of chalcogenide fibers for IR transmission have been documented (Sanghera et al., 2005a). Also of interest is the high nonlinearity of these glass compositions. The high $\chi^{(3)}$ nonlinearities of chalcogenide glasses make them excellent candidates for applications such as all optical processing, Raman amplification, parametric amplifiers and supercontinuum generation.

\section{Glass preparation}

Chalcogenide glasses are melted directly in quartz ampoules using chemicals purified via distillation/sublimation (Sanghera et al., 1994a). Typical melt temperatures range from $600^{\circ} \mathrm{C}$ to $900^{\circ} \mathrm{C}$, depending upon composition. The liquids are quenched and the glass rods annealed at temperatures around the appropriate softening temperatures. The optical fibers are obtained by the double crucible (DC) process (Sanghera et al., 1995). The DC process enables adjustments to be made in the core/clad diameter ratio during fiber drawing by independent pressure control above each melt. Therefore both multimode and single mode fibers can be drawn with relatively few processing steps.

\section{Fiber properties}

Figure 1 compares the losses routinely obtained for a couple of chalcogenide glasses along with the lowest ("champion") losses reported in the literature (Sanghera et al., 1994b; Churbanov, 1992). Depending upon composition, the sulfide, selenide and telluride based fibers transmit between about $0.8-7 \mu \mathrm{m}, 1-10 \mu \mathrm{m}$, and 2-12 $\mu \mathrm{m}$, respectively. Therefore, the practical applications dictate the type of fiber to be used. As-S fibers loss routinely achieved is about $0.1-0.2 \mathrm{~dB} / \mathrm{m}$ in fiber lengths of about 500 meters. Losses for As-Se fibers typically range from 0.5 to $1 \mathrm{~dB} / \mathrm{m}$ in the near IR around $1.5 \mu \mathrm{m}$.

Source: Frontiers in Guided Wave Optics and Optoelectronics, Book edited by: Bishnu Pal, ISBN 978-953-7619-82-4, pp. 674, February 2010, INTECH, Croatia, downloaded from SCIYO.COM 


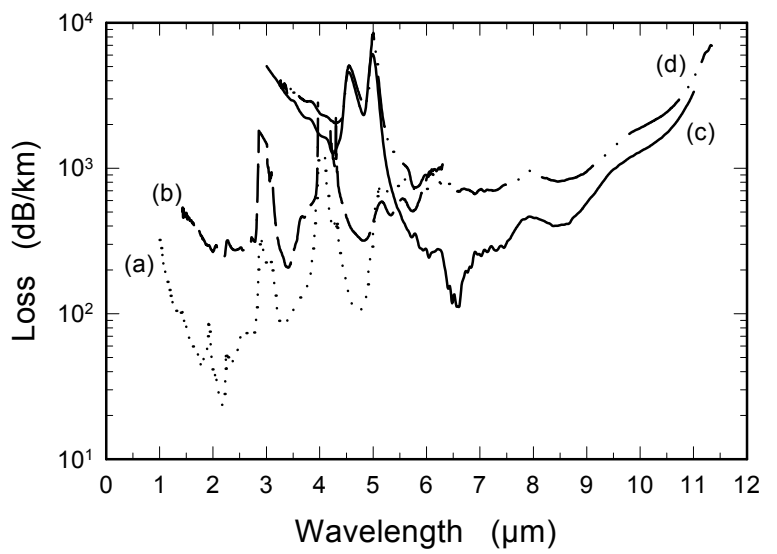

Fig. 1. Transmission loss spectra of (a) lowest loss sulfide fiber, (b) typical sulfide fiber, (c) lowest loss telluride fiber, and (d) typical telluride fiber.

\section{Nonlinear properties}

It is well established that the values of $\chi^{(3)}$ for chalcogenide glasses are about two orders of magnitude larger than silica (Nasu et al, 1989; Richardson et al, 1998). More recently, glasses have been reported with non-linearities approaching 1000 times silica (Lenz et al., 2000; Harbold et al., 2002). These large nonlinearities would allow small compact low power devices for telecommunications. The subpicosecond response of these nonlinearities is ideal for high data rate telecommunication devices.

For efficient nonlinear devices utilizing the optical Kerr effect, the nonlinearity must be high and the nonlinear absorption must be low. A figure of merit FOM $=n_{2} /(\beta \lambda)$ can be defined as a useful metric to determine optimum compositions, where $\mathrm{n}_{2}$ is the nonlinear index and $\beta$ is the nonlinear absorption. For isotropic medium, one and two photon resonant processes dominate the third-order susceptibility. For frequencies approximately half of the material resonance, two photon processes resonantly enhance the nonlinear index $\mathrm{n}_{2}$. Normally, however, the two photon resonance enhancement is accompanied by two photon absorption which competes with the nonlinear index $\mathrm{n}_{2}$. In the case of amorphous materials such as chalcogenide glass, an exponential Urbach tail exists and its absorption edge extends below the half gap. This edge leads to two photon absorption (TPA) below the half gap and thus $\mathrm{n}_{2}$ may increase faster than TPA absorption in this region. Consequently, the best performance in terms of nonlinear index strength vs. TPA (FOM) will occur just below the gap. Figure 2 shows the bandgap of the As-S-Se system vs. Se concentration.

Here, the bandgap is defined at the point of $10^{3} \mathrm{~cm}^{-1}$ absorption. In the graph, Se content of 0 at. \% corresponds to pure $\mathrm{As}_{40} \mathrm{~S}_{60}$ while Se content of 60 at. \% corresponds to pure $\mathrm{As}_{40} \mathrm{Se}_{60}$. The bandgap of the glass system decreases with Se content. For operation at $1.55 \mu \mathrm{m}(0.8$ $\mathrm{eV}$ ), we would expect an optimum composition of $\mathrm{As}_{40} \mathrm{Se}_{60}$ where $\mathrm{E}_{\mathrm{g}} / \mathrm{h} v \sim 0.45$. This is borne out by experimental data.

Spectrally resolved two beam coupling measurements of As-S-Se system have been performed to determine the magnitude of the nonlinear index $\mathrm{n}_{2}$ and the two photon 


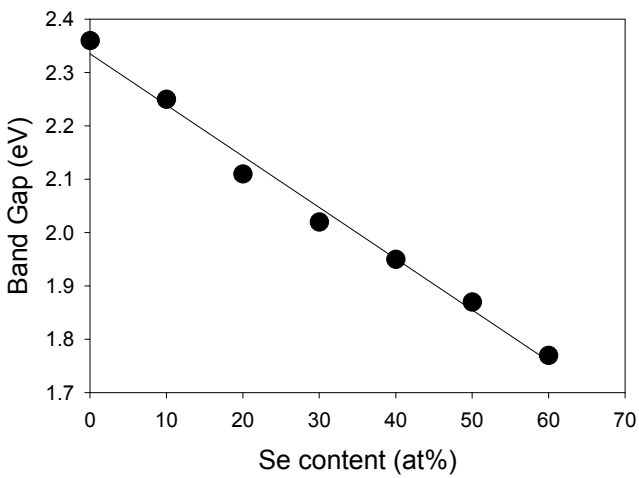

Fig. 2. Bandgap of As-S-Se glass system (defined at the point of $10^{3} \mathrm{~cm}^{-1}$ absorption).

absorption coefficient. Details of these measurements can be found in (Harbold et al., 2002). Figure 3 shows the results of these measurements. Values for As-S were found to be $\sim 220$ times higher than for silica at $1.55 \mu \mathrm{m}$ and increased with Se substitution of $S$ to a value of 930 times higher than silica for As-Se. Likewise, two photon absorption also increases with increasing Se content. This data can be used to calculate the FOM for the As-Se system (Figure 4). As expected, the glasses with the largest FOM for operation at $1550 \mathrm{~nm}$ occurs for $\mathrm{E}_{\mathrm{g}} / \mathrm{h} v$ at $\sim 0.45$ which is the As-Se composition (Slusher et al., 2004).

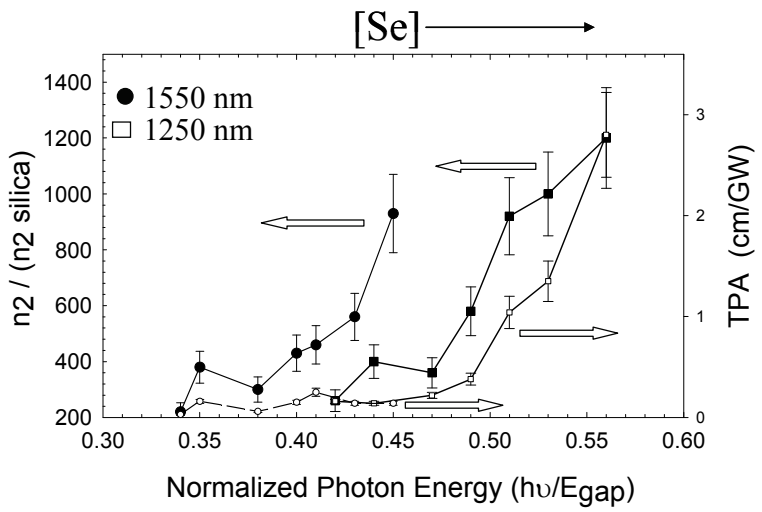

Fig. 3. $\mathrm{n}_{2}$ and TPA absorption of As-S-Se glass system.

High speed optical processing has been demonstrated by exploiting these high nonlinearities in chalcogenide glass fiber and waveguides. Earlier work on all optical switching in chalcogenide fiber was performed by Asboe (Asobe et. al. 1993) who demonstrated switching of an $80-\mathrm{GHz}$ pulse train in a 2 meter length of $\mathrm{As}_{2} \mathrm{~S}_{3}$ based fiber using an optical kerr shutter configuration. More recently, $640 \mathrm{~Gb} / \mathrm{s}$ demultiplexing has been demonstrated in a $5 \mathrm{~cm}$ long chalcogenide rib waveguide on silicon by utilizing FWM (Galili et. al. 2009). $40 \mathrm{~Gb} / \mathrm{s}$ all optical wavelength conversion has also been demonstrated in chalcogenide tapered fibers (Pelusi, et. al. 2008). Here, a CW laser at the conversion wavelength was modulated by XPM with the co-propagating $40 \mathrm{~Gb} / \mathrm{s}$ signal. 


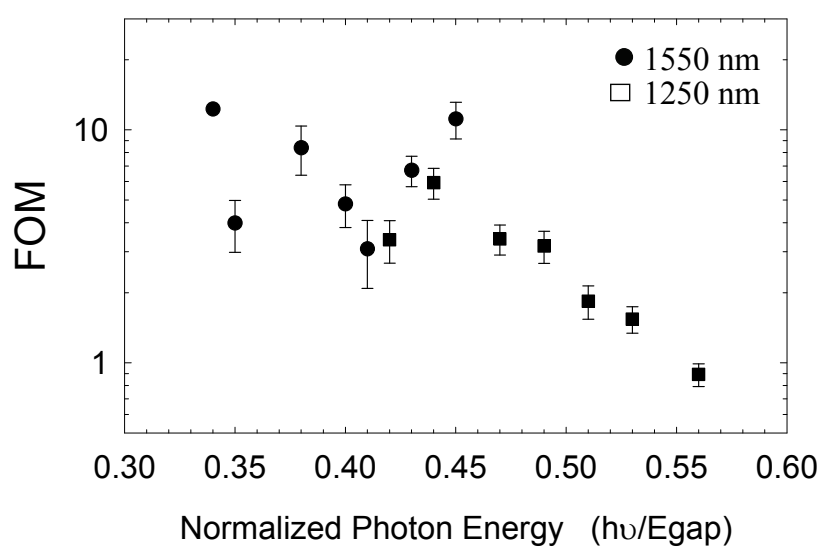

Fig. 4. FOM for As-S-Se glass system.

\section{Raman amplification}

Figure 5 shows the normalized Raman spectra of $\mathrm{As}_{40} \mathrm{~S}_{60}, \mathrm{As}_{40} \mathrm{Se}_{60}$, and silica. $\mathrm{As}_{40} \mathrm{Se}_{60}$ glass has a much narrower Raman line $\left(\sim 60 \mathrm{~cm}^{-1}\right)$ than silica glass $\left(\sim 250 \mathrm{~cm}^{-1}\right)$. In addition, the Raman shift for $\mathrm{As}_{40} \mathrm{Se}_{60}$ glass is much smaller $\left(\sim 240 \mathrm{~cm}^{-1}\right)$ than the Raman shift of silica glass $\left(\sim 440 \mathrm{~cm}^{-1}\right)$ due to the heavier atoms present in the chalcogenide glass. Previous studies have looked at stimulated Raman scattering in $\mathrm{As}_{40} \mathrm{~S}_{60}$ glass, a very similar glass system to $\mathrm{As}_{40} \mathrm{Se}_{60}$ (Asobe et al., 1995). These studies found the Raman gain coefficient of $\mathrm{As}_{40} \mathrm{~S}_{60}$ to be almost two orders of magnitude higher than that of silica. It was also found that this enhancement in the Raman gain roughly corresponded to the enhancement in the nonlinear index, $\mathrm{n}_{2}$. Consequently, one might expect to see an even larger Raman gain coefficient in $\mathrm{As}_{40} \mathrm{Se}_{60}$ since the selenide glass has shown an even larger nonlinearity and also a narrower Raman spectrum.

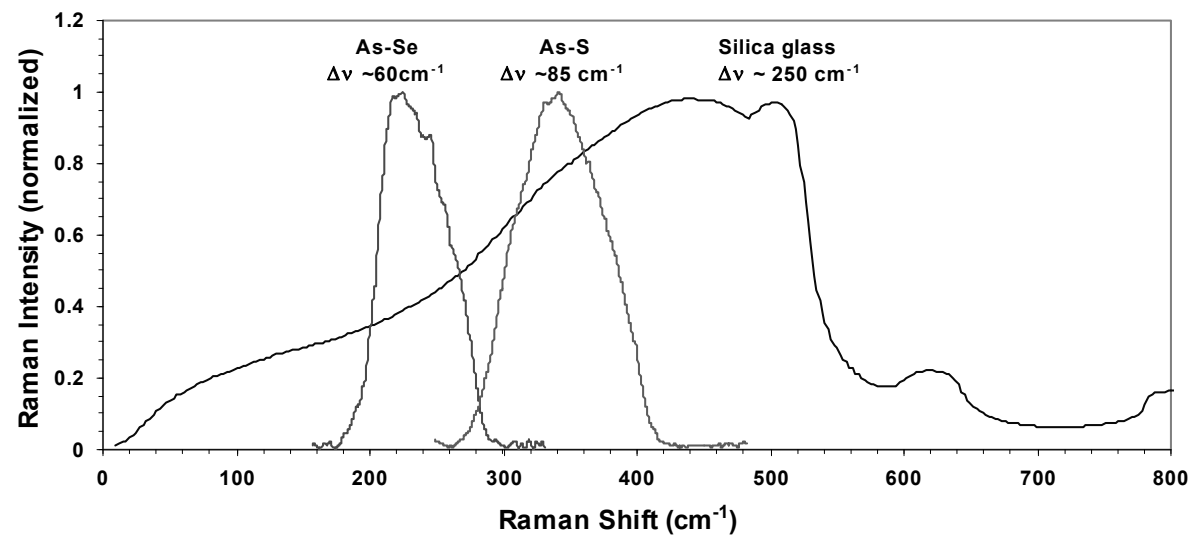

Fig. 5. Raman spectra of $\mathrm{As}_{2} \mathrm{~S}_{3}$ and $\mathrm{As}_{2} \mathrm{Se}_{3}$ glass. Silica glass is shown for reference. 
Raman amplification at $1.55 \mu \mathrm{m}$ has been demonstrated in small core As-Se fiber (Thielen et al., 2003a). The results of the Raman amplification experiment are shown in shown in Figure 6 . Over $\sim 23 \mathrm{~dB}$ of gain was achieved in a 1.1-meter length of fiber pumped by a nanosecond pulse of $\sim 10.8 \mathrm{~W}$ peak power at $1.50 \mu \mathrm{m}$. The peak of the Raman gain was shifted by $\sim 230$ $\mathrm{cm}^{-1}$ to $1.56 \mu \mathrm{m}$. The Raman gain coefficient was estimated to be $\sim 300$ times silica in this experiment. More recent measurements of the Raman gain coefficient show a value of about 780x greater than that of silica (Slusher et al. 2004).

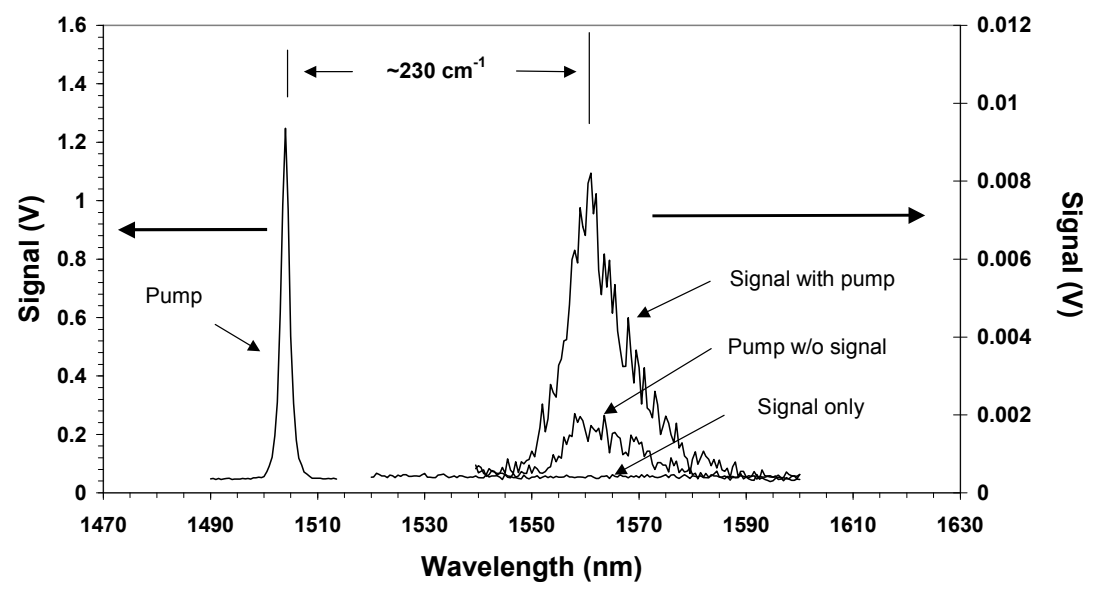

Fig. 6. Raman amplification in As-Se fiber. Shown is amplifier output with signal and no pump, pump and no signal (showing background stimulated Raman scattering (SRS) resulting from pump), and amplified signal with pump.

The large Raman gain coefficient of chalcogenide glass coupled with its large IR transparency show promise for lasers and amplifiers in the near and mid-IR. The potential for Raman lasers and amplifiers can be assessed by defining a figure of merit (FOM). The expression for single pass gain, $G_{A}$, in a Raman fiber laser is given by [1]:

$$
G_{A}=\exp \left(\frac{g_{R} P_{0} L_{e f f}}{A_{e f f}}\right)
$$

Where $g_{R}$ is the Raman gain coefficient, $P_{0}$ is the pump power, $A_{\text {eff }}$ is the fiber effective area and $L_{\text {eff }}$ is the fiber effective length. The fiber effective length is given by

$$
L_{\text {eff }}=\frac{1}{\alpha}\left(1-e^{-\alpha \cdot L}\right) \approx \frac{1}{\alpha}
$$

Where $\alpha$ is the fiber loss. For long lengths, $L_{e f f}$ is approx $1 / \alpha$. From these equations, the gain is proportional to $\exp \left(-g_{R} / \alpha\right)$ for long fiber lengths. Thus, the value $g_{R} / \alpha$ can be used as a rough FOM for Raman amplification. Table 1 compares the performance of an As-Se Raman fiber laser or amplifier operating at $4 \mu \mathrm{m}$ to a silica Raman fiber laser or amplifier operating in the telecommunications band at $1.5 \mu \mathrm{m}$. Here, the Raman gain coefficient of As-Se, $g_{R}$, which is measured to be $780 \mathrm{x}$ silica at $1.5 \mu \mathrm{m}$ is extrapolated to it value in the mid-IR since 
the Raman gain coefficient scales inversely with wavelength. $\alpha$ is the fiber loss. For silica, a loss of 0.2 to $0.3 \mathrm{~dB} / \mathrm{km}$ is typical of telecommunication grade fiber. For As-Se, two losses are given. The loss of $200 \mathrm{~dB} / \mathrm{km}$ is typical of "champion losses" achieved at NRL for As-Se fiber while the loss of $3 \mathrm{~dB} / \mathrm{km}$ is theoretical loss for As-Se fiber (Devyatykh et al., 1992). For the loss of $200 \mathrm{~dB} / \mathrm{km}, g_{R} / \alpha$ for an As-Se fiber Raman amplifier operating at $4 \mu \mathrm{m}$ is about 0.38 compared to 1.1 for a silica fiber Raman amplifier. For the theoretical loss of 3 $\mathrm{dB} / \mathrm{km}, g_{R} / \alpha$ for As-Se fiber operating at $4 \mu \mathrm{m}$ is 23 times that of silica fiber operating at $1.5-\mu \mathrm{m}$.

\begin{tabular}{|l|c|c|c|c|c|}
\hline & $\begin{array}{c}\lambda \\
(\mu \mathrm{m})\end{array}$ & $\begin{array}{c}\mathrm{g}_{\mathrm{R}} \\
(\mathrm{cm} / \mathrm{W})\end{array}$ & $\begin{array}{c}\text { Loss } \\
(\mathrm{dB} / \mathrm{km})\end{array}$ & $\alpha\left(\mathrm{cm}^{-1}\right)$ & $\begin{array}{c}\text { FOM } \\
\left(10^{-6} \mathrm{~W}^{-1}\right)\end{array}$ \\
\hline & & & & & \\
\hline Silica Fiber & 1.5 & $0.65 \times 10^{-12}$ & $0.2-0.3$ & $\sim 6 \times 10^{-7}$ & 1.1 \\
\hline As-Se Fiber & \multirow{2}{*}{4} & $1.7 \times 10^{-10}$ & 200 & $5 \times 10^{-4}$ & 0.34 \\
\cline { 4 - 6 } & & 3 & $7.5 \times 10^{-6}$ & 23 \\
\hline
\end{tabular}

Table 1. Figure of merit for Raman amplification in As-Se fiber at 4- $\mu$ m compared Raman amplification in silica fiber at $1.5-\mu \mathrm{m}$. The loss value of $200 \mathrm{~dB} / \mathrm{km}$ (a) for As-Se is typical of a "champion" loss value. The loss value of $3 \mathrm{~dB} / \mathrm{km} \mathrm{(b)}$ is theoretical loss.

A Raman laser has been demonstrated in As-Se fiber by Jackson (Jackson et. al. 2000). They generated $0.64 \mathrm{~W}$ of first Stokes at $2062 \mathrm{~nm}$ with a slope efficiency of $66 \%$ under $2051 \mathrm{~nm}$ pumping in a 1 meter length $6 \mu \mathrm{m}$ core, 0.19 NA fiber. Reflection off the endface of the fiber ( $\sim 22 \%$ at normal incidence) was used for feedback at the output end of the fiber while a broadband Au-coated mirror was used as a back reflector. Note that the braodband nature of the cavity reflectors allowed the Raman laser to oscillate on a number of vibrations. The line at $2062 \mathrm{~nm}$ was attributed to interlayer vibrations of $\mathrm{As}_{2} \mathrm{Se}_{3}$. Raman output at 2102 from bond bending vibrations and at $2166 \mathrm{~nm}$ for bond stretching vibrations were also observed. Stimulated Raman scattering (SRS) has been observed in the mid- IR. Figure 7 shows the SRS in a $\sim 1 \mathrm{~m}$ length of As-Se fiber under CW CO laser pumping at $\sim 5.4 \mu \mathrm{m}$. The SRS is seen at $\sim 6.1 \mu \mathrm{m}$. Raman laser operating in the wavelength range of from 6.1 to $6.4 \mu \mathrm{m}$ would have applications in laser surgery. These wavelengths correspond to amide bands in

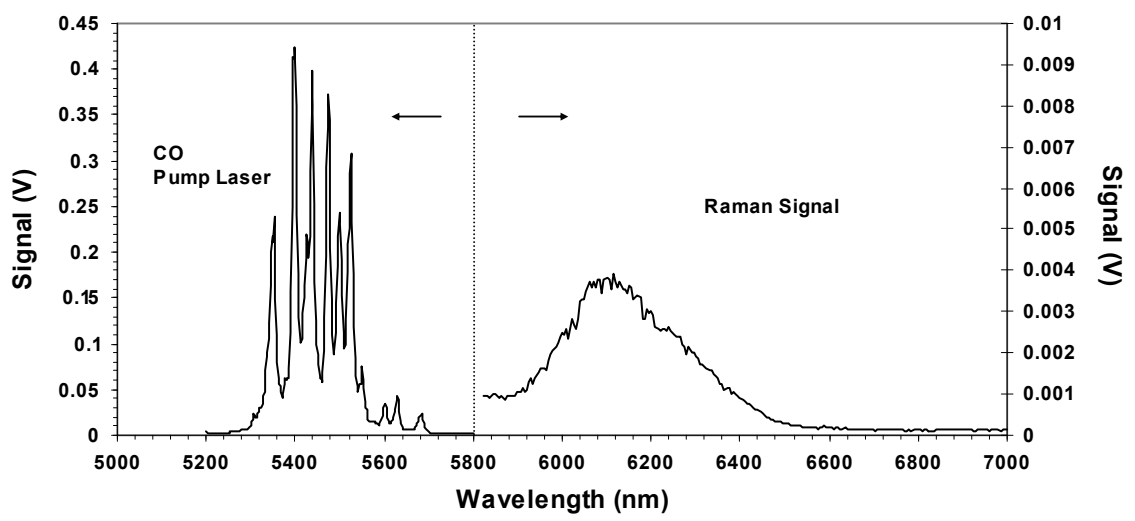

Fig. 7. SRS signal observed at $6.1 \mu \mathrm{m}$ under $\sim 5.4 \mu \mathrm{m}$ CO laser pumping. 
tissues and studies have shown that ablation of soft tissue is possible at these wavelengths with minimal collateral damage, thus accelerating healing (Edwards et al. 1994). Modeling of a Raman laser operating at $6.45 \mu \mathrm{m}$ under $\mathrm{CO}$ laser pumping at $5.59 \mu \mathrm{m}$ has shown high slope efficiencies and moderate threshold power operation is possible (Thielen et al. 2003b).

\section{Supercontinuum generation}

Supercontinuum generation has been demonstrated between 2 to $3 \mu \mathrm{m}$ in small core sulfide and selenide fibers as well as photonic crystal selenide fibers (PCF) (Shaw et al., 2005). The 1 meter length of fibers were pumped with a Ti:sapphire pumped OPA laser at a wavelength of $2.5 \mu \mathrm{m}$ using $100 \mathrm{fs}$ pulses and $100 \mathrm{pJ} /$ pulse. The outputs from the fibers are shown in figure 8 . The sulfide and selenide fibers were $7 \mu \mathrm{m}$ core diameter, while the PCF fiber had a $10 \mu \mathrm{m}$ core diameter. In all cases, pumping was in the normal dispersion region of the fibers and much of the broadening can be attributed to self phase modulation (SPM) with some broadening to the red due to Raman (Hu et. al., 2008).

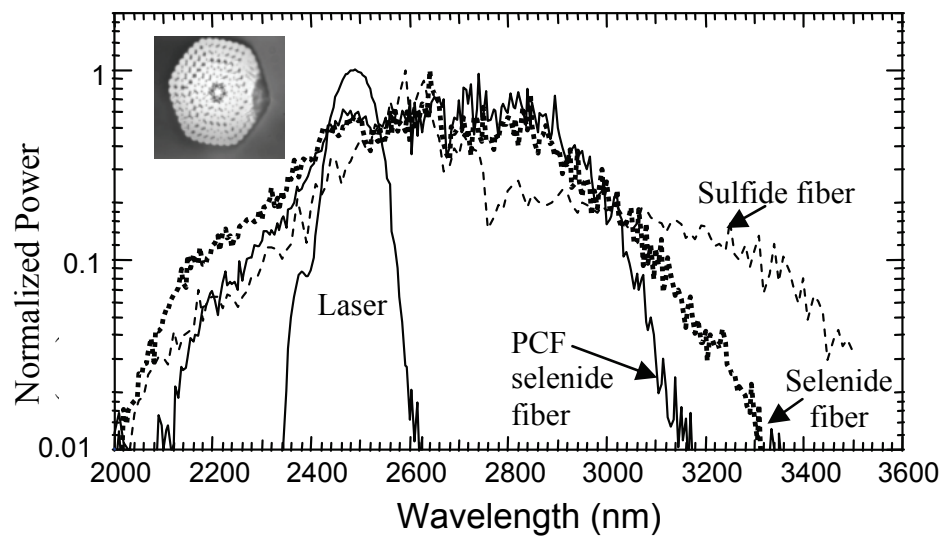

Fig. 8. Supercontinuum generation in small core chalcogenide fibers. The insert shows the cross-sectional view of the selenide PCF fiber.

By using chalcogenide glass PCF, the dispersion of the fiber by can controlled and the zero dispersion wavelength can be shifted to the near-IR making it feasible to pump in the anomalous dispersion region of the fiber with conventional near-IR fiber laser pumps. Modeling has shown that very broad supercontinuum bandwidths can be generated with properly designed chalcogenide PCF fiber and proper pump (Hu et. al. 2009)

\section{Poling of chalcogenide glass}

Isotropic materials such as glasses lack a center of inversion symmetry and thus have no second order nonlinear susceptibility $\left(\chi^{(2)}\right)$ they should not exhibit second harmonic generation (SHG) (Dianov et al., 1989). However, undoped and Pr-doped GaLaS glasses have exhibited SHG (De Aruajo et al., 1996) through optical pumping. This SHG may be due to crystallization or the effect of frozen-in electric fields. The latter arises from the relationship $\chi^{(2)}=\mathrm{E}_{\mathrm{dc}} \chi^{(3)}$, where $\mathrm{E}_{\mathrm{dc}}$ is the frozen-in electric field (Dianov et al., 1989). Electric 

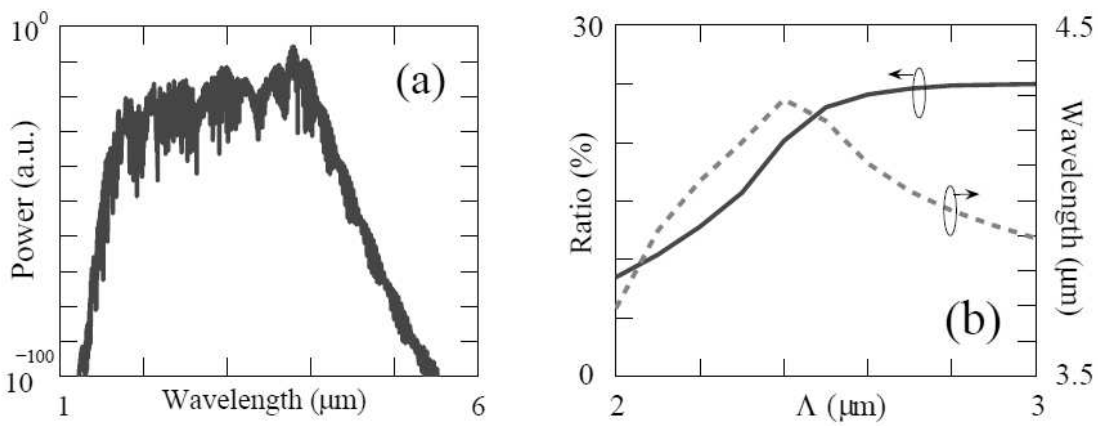

Fig. 9. (a) Modeled supercontinuum spectrum in As-S Photonic crystal fiber with $\Lambda=3 \mu \mathrm{m}$ under $2 \mu \mathrm{m}, 500 \mathrm{fs}, 1 \mathrm{~kW}$ peak power pumping. (b) The central wavelength of the soliton with the largest power (dashed curve) and the ratio of the power generated between $3 \mu \mathrm{m}$ and $5 \mu \mathrm{m}$ to the total input power as a function of the pitch at the end of the tapered PCF (solid curve) (Hu, et. al. 2009)

poling has been successfully used to produce SHG in silica based fiber systems (Kazansky et al., 1997). It is not unreasonable to expect similar results in chalcogenide fibers.

Since $\chi^{(3)}$ is about 2 to 3 orders of magnitude larger in chalcogenides compared with silica, we expect larger SHG efficiencies in electrically poled chalcogenide glasses. However, the question arises as to whether the electric fields can be frozen-in for chalcogenide glasses. Second harmonic generation has been observed at $780 \mathrm{~nm}$ using electrically poled arsenic sulfide glass when pumping a $1 \mathrm{~mm}$ thick arsenic sulfide glass disk at $1560 \mathrm{~nm}$ as shown in Figure 10. The sample was electrically poled at $100^{\circ} \mathrm{C}$ for 5 hours under nitrogen gas atmosphere. At the present time the magnitude appears comparable to silica glass but the mechanism is unknown.

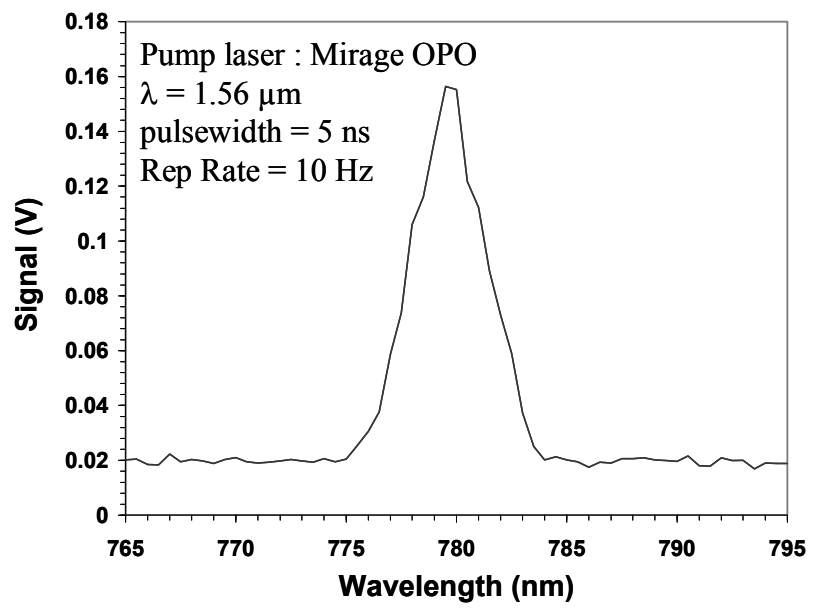

Fig. 10. Second harmonic generation in poled As-S glass. Glass was pumped at $1.56 \mu \mathrm{m}$. Shown is the $780 \mathrm{~nm}$ SHG signal. 


\section{Brillouin scattering}

In order to estimate the Brillouin gain coefficient, the threshold power of the stimulated Brillouin scattering (SBS) process can be measured using the experimental setup detailed in Fig. 11. The threshold power is easily determined by measuring the amount or monitoring the spectrum of the reflected light using a high-resolution optical spectrum analyzer (OSA) as sampled by the circulator. The fibers can be coated with liquid gallium on 10-cm lengths on each end to eliminate the radiation leaking into the cladding. In the example provided, the fiber ends were not anti-reflection coated and hence cavity effects were significant due to the high refractive index of the fiber. The losses in the fiber and in the coupling optics are all taken into account when estimating the amount of pump launched into the core. A $45 \%$ coupling efficiency was estimated in the $\mathrm{As}_{2} \mathrm{~S}_{3}$ case, and $37 \%$ in the $\mathrm{As}_{2} \mathrm{Se}_{3}$ case. These values can be optimized and hence the SBS threshold power can be reduced, which is desired trend from a system design perspective.

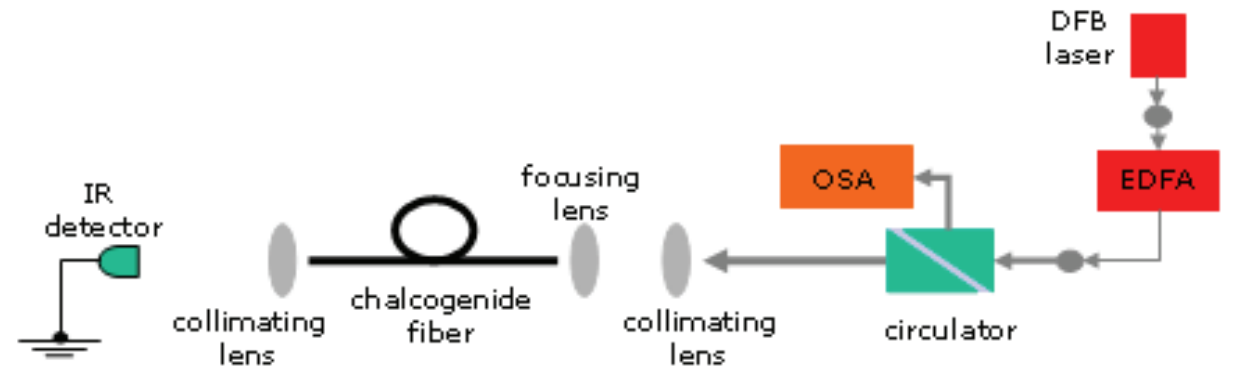

Fig. 11. Experimental setup used for SBS threshold measurements.

The spectral changes of the backward wave propagating through the chalcogenide fiber, as sampled by the circulator, are shown in Fig. 12 for the $\mathrm{As}_{2} \mathrm{~S}_{3}$ fiber, and in Fig. 13 for the $\mathrm{As}_{2} \mathrm{Se}_{3}$ fiber, respectively. The cavity effects reduced the accuracy of the threshold measurement as indicated in the captions. Nevertheless, the threshold is easily identified by the significant jump in the peak of the Brillouin-shifted signal monitored on the OSA. Additionally, clamping of the pump output power was observed, once the threshold was reached, since most of the pump power wastransfered to the Stokes wave (Ruffin, 2004).

The numerical aperture (NA) of a fiber determines the mode-field diameter and hence the effective area of the fundamental mode, with direct implications on the threshold power estimation for the SBS process. It also determines the number of modes supported by the fiber at a given wavelength, $\lambda$. The $\mathrm{V}$-number for a step-index fiber is a function of NA as given in Eq. 3, where $\mathrm{d}$ is the core diameter:

$$
\mathrm{V}=\frac{\pi \mathrm{d}}{\lambda} \mathrm{NA}
$$

A value of $\mathrm{V}=2.405$, or lower, indicates single mode behavior. The $\mathrm{V}$-number for the $\mathrm{As}_{2} \mathrm{~S}_{3}$ fiber used was $\sim 2.8$ During the experiments, the mode field pattern was monitored by imaging the output on a Vidicon camera to make sure only the fundamental mode was launched. Using the NA and V-number values, the Mode Field Diameter (MFD), $\mathrm{d}_{1 / \mathrm{e}^{2}}$, for the fundamental mode will be given by Eq. 4 and is listed in Table 2: 


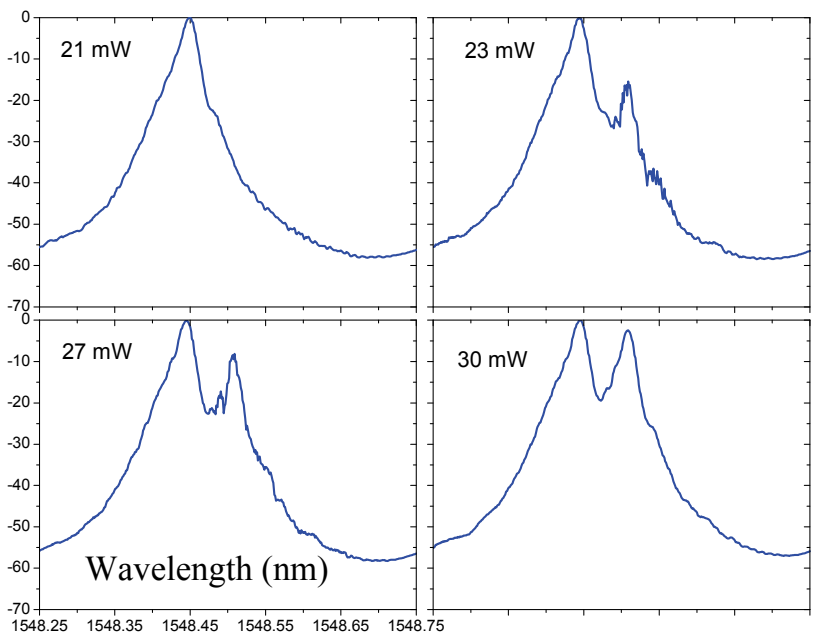

Fig. 12. Typical spectra of the reflected light sampled by the circulator for different launched pump powers into the $\mathrm{As}_{2} \mathrm{~S}_{3}$ fiber core. Fiber length was $10.0 \mathrm{~m}$. Estimated SBS threshold: $(27 \pm 3) \mathrm{mW}$. Tick labels shown only on one plot for clarity.

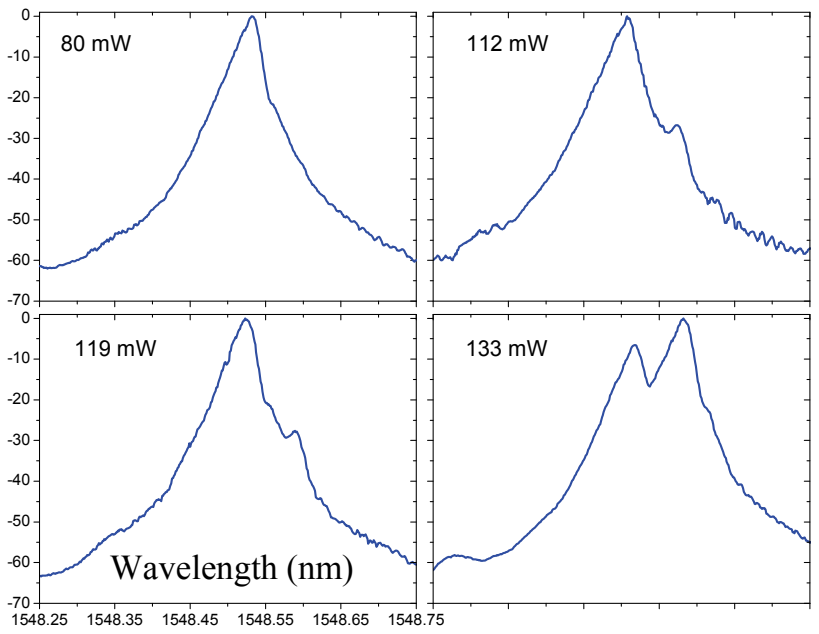

Fig. 13. Typical spectra of the reflected light sampled by the circulator for different launched pump powers into the $\mathrm{As}_{2} \mathrm{Se}_{3}$ fiber core. Fiber length was $5.0 \mathrm{~m}$. Estimated SBS threshold: $(127 \pm 7) \mathrm{mW}$. Tick labels shown only on one plot for clarity. 


$$
\mathrm{d}_{1 / \mathrm{e}^{2}}=\mathrm{d} \times\left(0.65+\frac{1.619}{\mathrm{~V}^{1.5}}+\frac{2.879}{\mathrm{~V}^{6}}\right)
$$

The propagation loss is also an important parameter as it defines the effective interaction length for the Brillouin scattering process. The values reported in Table 2 represent relatively low losses for both singlemode fibers at $1.56 \mu \mathrm{m}$. However, it should be possible to lower the losses even further by improved fiber drawing and glass fabrication processes.

\begin{tabular}{|c|c|c|c|c|c|c|c|}
\hline Fiber & $\begin{array}{c}\text { Core } \\
\text { dia. } \\
{[\mu \mathrm{m}]}\end{array}$ & $\begin{array}{c}\text { Clad } \\
\text { dia. } \\
{[\mu \mathrm{m}]}\end{array}$ & $\begin{array}{c}\text { Core } \\
\text { Refractive } \\
\text { Index }\end{array}$ & NA & $\begin{array}{c}\mathrm{V}- \\
\text { number }\end{array}$ & $\begin{array}{c}\mathrm{d}_{1 / \mathrm{e} 2 \mathrm{MFD}} \\
{[\mu \mathrm{m}]} \\
(\text { calculated })\end{array}$ & $\begin{array}{c}\text { Loss } \\
{\left[\mathrm{dB}^{-1} \mathrm{~m}^{-1}\right]}\end{array}$ \\
\hline $\mathrm{As}_{2} \mathrm{~S}_{3}$ & 4.2 & 142.0 & 2.45 & 0.33 & 2.8 & 4.2 & 0.57 \\
\hline $\mathrm{As}_{2} \mathrm{Se}_{3}$ & 6.5 & 175.0 & 2.81 & 0.14 & 1.8 & 9.0 & 0.90 \\
\hline
\end{tabular}

Table 2. Chalcogenide fiber parameters (at wavelength of $1.56 \mu \mathrm{m}$ ).

From the experimentally determined threshold power values (Pth) shown in figures 12 and 13, one can estimate the Brillouin gain coefficient $\left(\mathrm{g}_{\mathrm{B}}\right)$ using Eq. 5 (Song et al, 2006; Ippen and Stolen, 1972):

$$
\mathrm{P}_{\text {th }} \cong 21 \frac{\mathrm{A}_{\text {eff }}}{\mathrm{L}_{\text {eff }} \mathrm{g}_{\mathrm{B}} \mathrm{k}}
$$

In the Eq. $5, \mathrm{k}$ is a constant which reflects whether the polarization is maintained constant throughout the interaction $(\mathrm{k}=1)$ or not $(\mathrm{k}=0.5$, our case). Also, the Aeff and Leff are the effective area of the fundamental mode, and the effective interaction length, respectively. These are given by Eq. 6 and Eq. 7, where L is the fiber length, $\alpha$ is the propagation loss, and the mode-field diameter is determined by Eq. 3 above.

$$
\begin{gathered}
\mathrm{A}_{\text {eff }}=\frac{\pi \mathrm{d}_{1 / \mathrm{e}^{2}}^{2}}{4} \\
\mathrm{~L}_{\text {eff }}=\frac{1}{\alpha}\left(1-\mathrm{e}^{-\alpha \mathrm{L}}\right)
\end{gathered}
$$

Using Eqs. 5-7, the parameters from Table 3, and the fiber lengths and pump threshold values indicated in Fig. 11 and Fig. 12, The Brillouin coefficient is estimated to be $(3.9 \pm 0.4) \times 10^{-9}$ $\mathrm{m} . \mathrm{W}^{-1}$ for the $\mathrm{As}_{2} \mathrm{~S}_{3}$ and $(6.75 \pm 0.35) \times 10^{-9} \mathrm{~m} . \mathrm{W}^{-1}$ for $\mathrm{As}_{2} \mathrm{Se}_{3}$. The value for the $\mathrm{As}_{2} \mathrm{Se}_{3}$ is close to the only other previously published result for this composition (Song et al, 2006). The value for the $\mathrm{As}_{2} \mathrm{~S}_{3}$ fiber, although lower than the one for $\mathrm{As}_{2} \mathrm{Se}_{3}$, is still two orders of magnitude higher than that for fused silica $\left(\sim 4.4 \times 10^{-11} \mathrm{~m} . \mathrm{W}^{-1}\right)$ (Song et al, 2006; Ogusu et al., 2004).

\section{Slow light}

The slow-light technique based on stimulated Brillouin scattering (SBS) in optical fibers has attracted interest as it allows a very simple and robust implementation of tunable optical pulse delays, using mostly standard telecom components. Especially important are nonsilica-based fibers with higher nonlinearity since these require lower powers and shorter lengths for practical implementations. 
To date, there have been reports of slow-light generation in Bi-oxide high-nonlinearity fiber (Jáuregui, C. et al., 2006), telluride fiber (Abedin, K., 2008) and of very efficient slow and fast light generation in $\mathrm{As}_{2} \mathrm{Se}_{3}$ chalcogenide fiber (Song, K. et al., 2006). Additionally, the SBS process has been studied in $\mathrm{As}_{2} \mathrm{~S}_{3}$ glass fibers (Florea et al., 2006). The very large Brillouin gain coefficient presents the chalcogenide fibers as alternatives to silica fiber for slow-light applications. A figure of merit (FOM) has been proposed (Song et al., 2006) in order to quantify the usefulness of a given fiber for slow-light based applications. The Brillouin gain is considered a positive factor while the length, the refractive index, and the power are considered as negative factors impacting the response time and the onset of additional nonlinear effects in the system. The FOM (Song et al., 2006) requires knowledge of the actual Brillouin gain which has to be measured, and takes into account the effective length not the total length of fiber. One can re-write the FOM such as to reduce it to the primary quantities describing the fiber (effective area, length and propagation loss, refractive index, and Brillouin gain coefficient expressed in $\mathrm{dB}$ ):

$$
\text { FOM } \equiv \frac{\text { Gain }[\mathrm{dB}]}{\mathrm{P}_{\mathrm{p}} \mathrm{nL}}=\frac{10 \times \log \left(\exp \left(\mathrm{g}_{\mathrm{B}} \mathrm{k} \frac{\mathrm{P}_{\mathrm{p}}}{\mathrm{A}_{\text {eff }}} \mathrm{L}_{\text {eff }}\right)\right)}{\mathrm{P}_{\mathrm{p}} \mathrm{nL}}
$$

The FOM can be further reduced to:

$$
\mathrm{FOM}=4.34 \frac{\mathrm{g}_{\mathrm{B}} \mathrm{kL}_{\text {eff }}}{\mathrm{nA}_{\text {eff }} \mathrm{L}}
$$

It is important to keep in mind that this FOM essentially determines what length and power are needed in a system to achieve a certain gain, and hence a certain time delay. The FOM as defined above in Eq. 9 tends to be a quantity which obscures the physical meaning contained in Eq. 8. Actually, the theoretical gain $\left(\mathrm{G}_{\text {th }}\right)$, expressed in $\mathrm{dB}$, as given by $\mathrm{Eq} 10$, could be used instead to compare different fibers, if one considers a standard fiber length of $1 \mathrm{~m}$ and a standard pump power of $1 \mathrm{~mW}$. Then, the theoretical gain is given by Eq. 10:

$$
\mathrm{G}_{\text {th }}[\mathrm{dB}]=4.34 \frac{\mathrm{g}_{\mathrm{B}} \mathrm{k} \times 1 \mathrm{~mW} \times\left.\mathrm{L}_{\text {eff }}\right|_{\mathrm{L}=\mathrm{lm}}}{\mathrm{A}_{\text {eff }}}
$$

One can use this last, fairly simple expression to compare the most representative fibers considered so far: silica (Song et al., 2005; Ruffin et al., 2005), high-nonlinearity bismuth fiber (Jáuregui et al., 2006; Lee et al. 2005), $\mathrm{As}_{2} \mathrm{Se}_{3}$ fiber (Song et al., 2006), along with the results reported here. The comparison is provided in Table 3, with all the data reported for experiments without polarization control $(\mathrm{k}=0.5)$. Also included is the FOM as defined above for completion. One can easily notice the significant increase in the theoretical gain (or FOM) for the $\mathrm{As}_{2} \mathrm{~S}_{3}$ fiber due to its smaller core, lower loss and slightly reduced refractive index.

A typical experimental setup for slow light demonstration using chalcogenide fiber is detailed in Figure 14. The components contained within the dashed contour lines were only employed for the delay measurements. The output of a DFB laser (at $1548 \mathrm{~nm}$ ) was split in two components, one which will serve as a pump while the other will serve as a counterpropagating signal. 


\begin{tabular}{|c|c|c|c|c|c|}
\hline & Silica [a] & Bi-HNL [b] & $\mathrm{As}_{2} \mathrm{Se}_{3}[\mathrm{c}]$ & $\mathrm{As}_{2} \mathrm{Se}_{3}$ & $\mathrm{As}_{2} \mathrm{~S}_{3}$ \\
\hline $\mathrm{N}$ & 1.47 & 2.22 & 2.81 & 2.81 & 2.45 \\
\hline Aeff [m²] & $6.78 \times 10^{-11}$ & $0.3 \times 10^{-11}$ & $3.94 \times 10^{-11}$ & $6.31 \times 10^{-11}$ & $1.39 \times 10^{-11}$ \\
\hline loss [dB.m-1] & 0.001 & 0.91 & 0.84 & 0.90 & 0.57 \\
\hline $\mathrm{L}[\mathrm{m}]$ & 2.0 & 2.0 & 5.0 & 5.0 & 10.0 \\
\hline Leff [m] & 2.0 & 1.63 & 3.23 & 3.1 & 5.6 \\
\hline $\mathrm{g}_{\text {в }}\left[\mathrm{m} . \mathrm{W}^{-1}\right]$ & $4.40 \times 10^{-11}$ & $6.43 \times 10^{-11}$ & $6.10 \times 10^{-9}$ & $6.75 \times 10^{-9}$ & $3.90 \times 10^{-9}$ \\
\hline $\mathrm{G}_{\text {th }}[\mathrm{dB}]$ & $\mathbf{0 . 0 7 6}$ & $\mathbf{0 . 0 0 3}$ & $\mathbf{1 . 0 8 4}$ & $\mathbf{0 . 7 1 9}$ & $\mathbf{3 . 3 9 8}$ \\
\hline FOM [dB.W-1. $\left.\mathbf{m}^{-1}\right]$ & $\mathbf{1}$ & $\mathbf{1 7}$ & $\mathbf{7 7}$ & $\mathbf{5 1}$ & $\mathbf{1 3 9}$ \\
\hline
\end{tabular}

[a] Song et al.,2005; Ruffin et al., 2005 ; [b] Jáuregui et al., 2006 ; [c] Song et al., 2006

Table 3. Comparison of figure of merit for slow-light based applications at $1.56 \mu \mathrm{m}$.

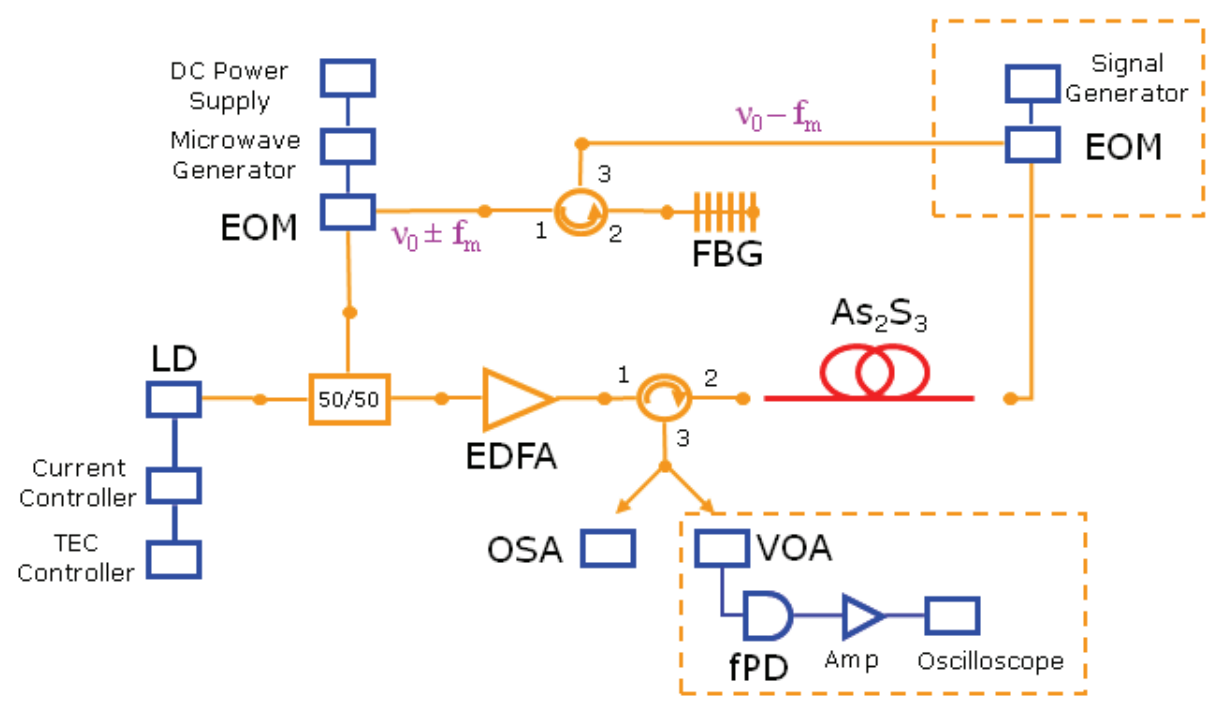

Fig. 14. Experimental setup used for gain and delay (dashed contour line) measurements. Abbreviations: LD - laser diode, EOM - electro-optical modulator, FBG - fiber Bragg grating filter, EDFA - Er-doped fiber amplifier, VOA - variable optical attenuator, fPD - fast photodiode, Amp - electrical amplifier.

The signal component is frequency shifted by a certain amount $\left(\mathrm{f}_{\mathrm{m}}\right)$ such as to match the Brillouin shift. Using a $\mathrm{LiNbO}_{3}$ modulator and a signal generator one can generate two sidebands which are then separated by using a fiber Bragg grating (FBG) filter. The center frequency is suppressed through DC biasing. For the gain measurements, the signal is coupled into the chalcogenide fiber and the output is monitored with an OSA. For the delay measurements, the signal, prior to being coupled into the fiber, is modulated (sine wave at $25 \mathrm{MHz}$ ) with a $\mathrm{LiNbO}_{3}$ modulator and a DS345 signal generator. The output is then passed through a variable optical attenuator (VOA) and detected with a fast photodiode and an amplifier on an oscilloscope. The VOA allowed us to control the signal on the detector such 
that we maintained the same signal (as low as possible) throughout the gain measurement to avoid any electronics-induced time response.

The pump is amplified with a standard EDFA and passed through a circulator before being coupled into the chalcogenide fiber, counter-propagating with the signal. The circulator allows us the signal to be picked off and sent to the detector.

The in-house drawn fiber used in this work was similar to the one used in previous work (Florea et al., 2006) but this time the fiber was cabled and both ends were antireflection coated. The fiber had a core of $5.2 \mu \mathrm{m}$ diameter and a clad of $150 \mu \mathrm{m}$ diameter, while the loss at $1550 \mathrm{~nm}$ was measured to be $0.138 \mathrm{~m}^{-1}\left(0.6 \mathrm{~dB} \cdot \mathrm{m}^{-1}\right)$. The effective area of the fundamental mode was measured and the critical power, $\mathrm{P}_{\text {th }}$, for a $10-\mathrm{m}$ length of fiber was determined, directly from the variation, with pump power, of the counter-propagating signal generated through Brillouin scattering. This was done in order to check the previous estimate of the $g_{B}$ coefficient (Florea et al., 2006), which was obtained by rather qualitatively analyzing the spectral changes of signal. By using $A_{\text {eff }}$ and $P_{c r}$ to determine $g_{B}$ as detailed below, this approach follows the method used in previous work (Song et al., 2006; Abedin, 2006) although a more exact analysis was proposed elsewhere (Ogusu, 2002).

The effective area $\left(\mathrm{A}_{\text {eff }}\right)$ was measured by imaging the fiber output on a vidicon camera using an appropriate microscope objective. $A_{\text {eff }}$ was measured directly rather than use a theoretical estimate (Song et al., 2006) due to the fact that the fiber had a very high NA (greater than 0.30) making it possible for a second, higher order mode to contribute to the fundamental mode field. The measuring system was calibrated by also imaging a patch of SMF28 fiber with well known mode-field diameter (MFD) of $10.4 \pm 0.8 \mu \mathrm{m}$ at $1550 \mathrm{~nm}$. The MFD for the chalcogenide fiber was thus determined to be $5.2 \pm 0.4 \mu \mathrm{m}$.

The critical power was measured by monitoring the intensity of the Brillouin scattered signal versus the launched, counter-propagating pump power. A more precise analysis is usually performed in silica fibers (Ruffin et al., 2005). The coupling efficiency was estimated from fiber throughput measurements. The reflected signal was collected using a circulator, and the values of the Brillouin peak were read directly from the optical spectrum analyzer (OSA). Several measurements were made which yielded an average $\mathrm{P}_{\text {th }}$ of $29 \pm 6 \mathrm{~mW}$, which is close to the previously reported value (Florea et al., 2006) of $27 \pm 3 \mathrm{~mW}$. A typical data set is shown in Figure 15.

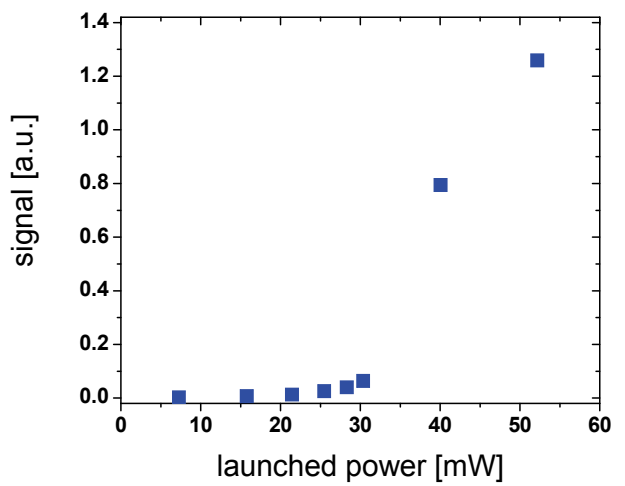

Fig. 15. Brillouin scattered signal in $\mathrm{As}_{2} \mathrm{~S}_{3}$ fiber versus launched pump power. 
Using Equation 7, in which $\alpha$ is the fiber loss and $L$ is the fiber length, an estimate of the effective fiber length (Leff) can be obtained, giving a value of $5.4 \mathrm{~m}$. Finally, one can use these values for $\mathrm{A}_{\mathrm{eff}}, \mathrm{P}_{\text {th, }}$ and $\mathrm{L}_{\mathrm{eff}}$, to estimate the Brillouin scattering coefficient using Equation 5, where $\mathrm{k}=0.5$, in this case. Using proper error analysis, the Brillouin scattering coefficient was determined to be $(5.7 \pm 2.0) \times 10^{-9} \mathrm{~m} . \mathrm{W}^{-1}$ for the $\mathrm{As}_{2} \mathrm{~S}_{3}$ fiber.

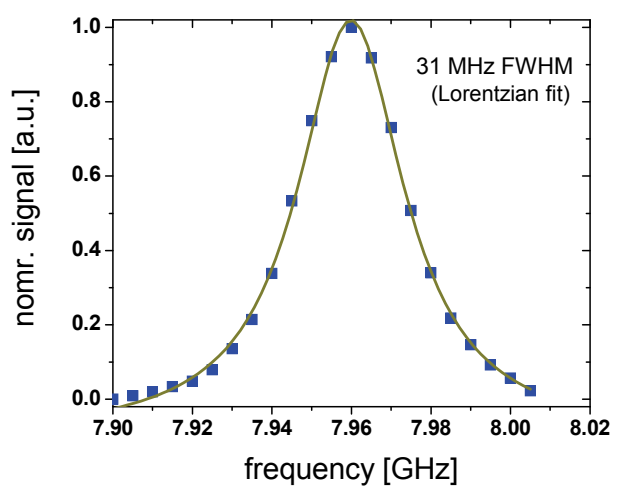

Fig. 16. Typical linewidth of the Brillouin signal at low pump power.

Additionally, the linewidth of the Brillouin signal was measured using a small probe $(\sim 8$ $\mu W)$ launched counter-propagating through the fiber. The Brillouin shift was identified to be $7.96 \mathrm{GHz}$ while the linewidth of the Brillouin shift was found to be $31 \mathrm{MHz}$ with typical data being represented in Figure 16. The linewidth was measured at low pump powers. Linewidth narrowing was observed for higher powers with linewidths as small as $19 \mathrm{MHz}$ being recorded.

Gain and delay measurements using a small signal $(\sim 8 \mu \mathrm{W})$ have been performed in the chalcogenide fiber. For the gain measurement, the signal peak values were read from the OSA for different pump powers. For the delay measurement, the relative shift of the sine wave was read from the oscilloscope. Typical set of traces is shown in Figure 17.

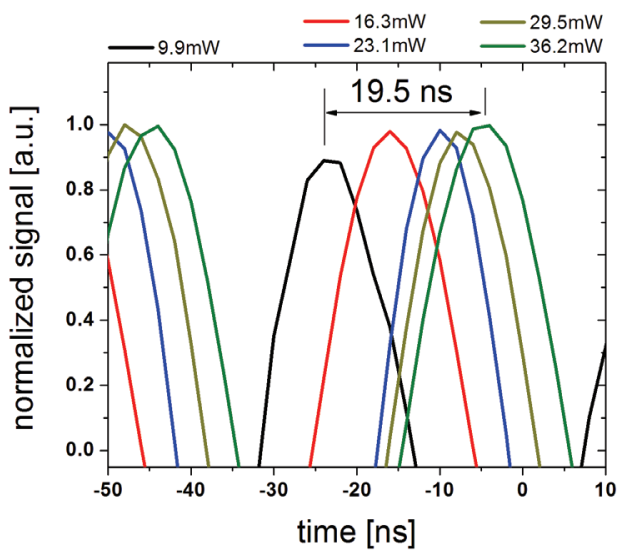

Fig. 17. Typical waveforms showing the delay for different pump powers. 
The observable gain and delay were limited by the damage threshold of the AR coating, which unfortunately was lower than the threshold for the bare $\mathrm{As}_{2} \mathrm{~S}_{3}$ glass. A slow variation of the amplified signal was observed which perhaps was due to the lack of polarization control in the setup. The overall results are represented in Figure 18.

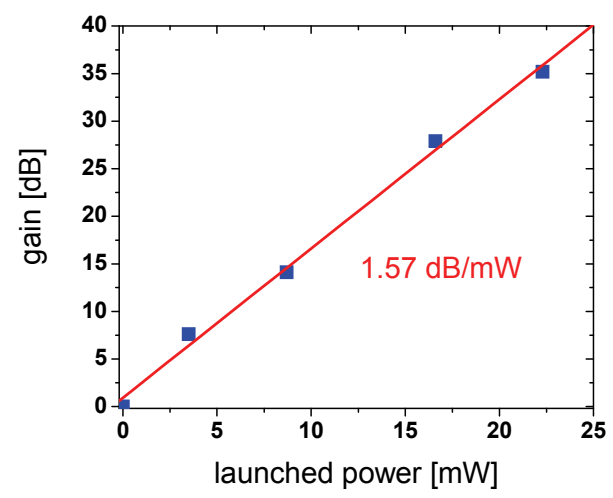

(a)

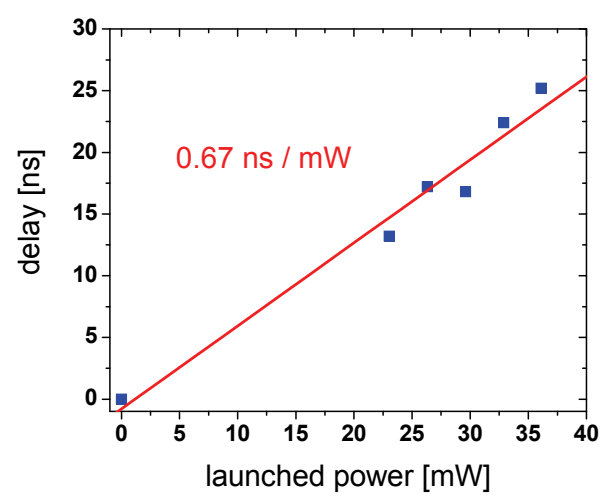

(b)

Fig. 18. (a) Gain and (b) pulse delay measurements in 10-m long $\mathrm{As}_{2} \mathrm{~S}_{3}$ fiber at $1548 \mathrm{~nm}$.

The slope of gain-versus-power is twice as large as the best previously reported result (Abedin, 2008). This was expected based on the analysis of the figure of merit (FOM) for the SBS process in these fibers (Song et al., 2006; Florea et al., 2006). However, the gain slope falls short of the theoretical estimate. Using the undepleted pump approximation, the smallsignal gain is given theoretically by Equation 11:

$$
\mathrm{G}_{\mathrm{th}}[\mathrm{dB}]=4.34 \frac{\mathrm{g}_{\mathrm{B}} \times \mathrm{k} \times \mathrm{L}_{\text {eff }}}{\mathrm{A}_{\text {eff }}} \times \mathrm{P}
$$


Using the experimentally determined values for the involved parameters along with the associated uncertainties, Equation 11 gives us a slope in the range [1.8 .. 5.0] dB.mW-1.

Inhomogenities in the fiber core diameter which we have noticed, the potential presence of a second mode and the pump depletion approximation can be viewed as factors contributing to the discrepancy.

The same factors can also influence the delay data. Once again one can predict theoretically how much the peak of the signal pulse would be delayed $(\Delta t)$ assuming an undepleted pump. The group velocity (given by $\mathrm{v}_{\mathrm{g}}=\mathrm{c} / \mathrm{n}_{\mathrm{g}}, \mathrm{c}-$ speed of light, $\mathrm{n}_{\mathrm{g}}$ total fiber group index) determines the time that a given pulse will take to travel the effective length of fiber. In the presence of the pump, the group velocity at the peak of the Brillouin gain will be modified according to Equation 12 (Okawachi et al., 2005), where $\Delta v$ is the linewidth (full-width halfmaximum) of the Brillouin shift:

$$
\frac{1}{\mathrm{v}_{\mathrm{g}}}=\frac{n_{f g}}{c}+\frac{G / L_{e f f}}{2 \pi \times \Delta v}
$$

For a narrow linewidth pulse the delay, that is difference between the transit times required by the pulse with and without the pump, will then be given by Equation 5 (Okawachi et al., 2005):

$$
\Delta \mathrm{t} \approx \frac{\mathrm{G}}{2 \pi \times \Delta v}=\frac{\mathrm{g}_{\mathrm{B}} \times \mathrm{k} \times \mathrm{L}_{\mathrm{eff}}}{\mathrm{A}_{\mathrm{eff}} \times 2 \pi \times \Delta v} \times \mathrm{P}
$$

Using the experimentally determined values for the involved parameters along with the associated uncertainties, Equation 13 gives us a slope in the range [2.1 .. 5.9] ns.mW-1. For this type of fiber, Equation 13 indicates theoretically that delays on the order of $100 \mathrm{~ns}$ or more can be obtained for reasonable powers.

While in practical terms a 19 ns delay was obtained for only $31 \mathrm{~mW}$ of pump power, which is marginally better than the result in the $\mathrm{As}_{2} \mathrm{Se}_{3}$ fiber (Abedin, 2008), these experimental values fall short of the theoretical expectations. The choice of the $25 \mathrm{MHz}$ frequency for modulation of the signal was unfortunate since it turned out to be too close to the Brillouin linewidth, especially at low powers. Future work will try different modulation parameters and will also provide a study to gain an insight into the nature and origin of fiber imperfections and the role of polarization which can negatively influence the performance of this system. This understanding will pave the way forward for delays of the order of 20 ns with as little as $10 \mathrm{~mW}$ of launched power.

\section{Conclusions}

The large nonlinearities and fast response of the nonlinearity of the As-S-Se system make fibers drawn from these glasses well suited for optical switches, optical regenerators for high speed telecommunication systems. Use of these materials will allow compact devices $\mathrm{cm}^{\prime} \mathrm{s}$ in length with optical powers $<1 \mathrm{~W}$ peak power (1 $\mathrm{pJ}$ in $1 \mathrm{ps}$ pulses). The large Raman gain of the As-S-Se fibers coupled with the large IR transparency make these well suited for compact Raman amplifiers for telecommunications as well as fiber lasers and amplifiers in the mid-IR. These high nonlinearities also allow efficient supercontinuum generation which 
is useful for broadband sources in the near and mid-IR. Finally these materials can be poled to induce an effective $\chi^{(2)}$, opening up the potential of waveguide parametric amplifiers.

The stimulated Brillouin scattering process was studied in $\mathrm{As}_{2} \mathrm{~S}_{3}$ and $\mathrm{As}_{2} \mathrm{Se}_{3}$ single mode fibers. Values of the Brillouin gain coefficient were measured to be $(3.9 \pm 0.4) \times 10^{-9} \mathrm{~m} . \mathrm{W}^{-1}$ and $(6.75 \pm 0.35) \times 10^{-9} \mathrm{~m} . \mathrm{W}^{-1}$, respectively. An analysis of the figure of merit for slow-light based applications indicates that the smaller core $\mathrm{As}_{2} \mathrm{~S}_{3}$ fiber performs best due to the lower loss, reduced core size and slightly lower refractive index. The configuration using the small-core $\mathrm{As}_{2} \mathrm{~S}_{3}$ fiber yields a figure of merit which is about 140 times larger, or a theoretical gain about 45 times larger, than the best silica-based configurations reported to date.

The continued improvement of chalcogenide materials will make such devices feasible in the near term.

\section{References}

Abedin, K. (2006). Observation of strong stimulated Brillouin scattering in single-mode $\mathrm{As}_{2} \mathrm{Se}_{3}$ chalcogenide fiber. Opt. Express 13, pp. 10266-10271.

Abedin, K.; Lu, G. and Miyazaki, T. (2008). Electron. Lett 44 , pp. 16.

Asobe, M.; Kanamori, T.; Naganuma, K.; Itoh, H. and Kaino, T. (1995). Third-order nonlinear spectroscopy in $\mathrm{As}_{2} \mathrm{~S}_{3}$ chalcogenide glass fibers. J. Appl. Phys. 77, pp. 5518-5523.

Asobe, M; Kobayashi, H; Itoh, H; and Kanamoir, T; (1993) Laser-diode-driven ultrafast alloptical switching by using highly nonlinear chalcogenide glass fiber, Opt Lett, 18, pp. 1056-1058.

Borisova, Z. (1981). Glassy Semicondutors, Borisova, Z. (Ed.), Plennum Press, NY, USA.

Churbanov, M. (1992). J. Non-Cryst. Solids, Vol. 140, pp. 324.

De Aruajo, M.; Vermelho, M.; Gouveia-Net, A.; Sombra, A. and Medeiros Neto, J. (1996). IEEE Photonics Technol. Letts., Vol. 8, pp. 821.

Devyatykh, G.; Churbanov, M.; Scripachev, I.; Dianov, E. and Plotnichenko, V. (1992). International Journal of Optoelectronics, Vol. 7, pp. 237-254.

Dianov, E.; Kazansky, P. and Stepanov, D. (1989). Sov. J. Quant. Electron., Vol. 19, pp. 575.

Edwards, G.; Logan, R.; Copeland, M.; Reinisch, L.; Davidson, J.; Johnson, B.; Maciunas, R.; Mendenhall, M.; Ossoff, R.; Tribble, J.; Wekhaven, J. and O'Day, D. (1994). Nature, Vol. 371, pp. 416-418.

Florea, C.; Bashkansky, M.; Dutton, Z.; Sanghera, J. \& Aggarwal, I. (2006) Stimulated Brillouin scattering in single-mode $\mathrm{As}_{2} \mathrm{~S}_{3}$ and $\mathrm{As}_{2} \mathrm{Se}_{3}$ chalcogenide fibers. Opt. Express, 14, 12063-12070.

Galili, M; Xu, J; Mulvad, H; Oxenlowe, L; Clausen, A; Jeppesen, P; Luther-Davies, B; Madden, S; Rode, A; Choi, D; Pelusi, M; Luan, F; and Eggleton, B (2009) Breakthrough switching speed with an all-optical chalcogenide glass chip: 640 Gbit/s demultiplexing, Opt. Exp, 17, pp. 2182-2187

Harbold, J.; Ilday, F.; Wise, F.; Sanghera, J.; Nguyen, V.; Shaw, L. and Aggarwal, I. (2002) Optics Letters, Vol. 27, pp. 119.

Hu, J.; Menyuk, C., Shaw, L., Sanghera, J., and Aggarwal, I., (2009) Generating mid-IR source using $\mathrm{As}_{2} \mathrm{~S}_{3}$-based chalcogenide photonic crystal fibers, Proc. Conference on Lasers and Electro-Optics (CLEO) 2009, Optical Society of America 
Hu, J.; Menyuk, C., Shaw, L., Sanghera, J., and Aggarwal, I., (2008) Raman response function and supercontinuum generation in chalcogenide fiber, Proc. Conference on Lasers and Electro-Optics (CLEO) 2008, Optical Society of America

Ippen, E. and Stolen, R. (1972). Stimulated Brillouin scattering in optical fibers. Appl. Phys. Lett., 21, pp. 539-541.

Jackson, S; and Anzueto-Sanchez, G; (2006) Chalcogenide glass Raman fiber laser, Appl. Phys. Lett., 88, p. 221106

Jáuregui, C.; Ono, H.; Petropoulos, P. and Richardson, D. (2006). Four-fold reduction in the speed of light at practical power levels using Brillouin scattering in a 2-m bismuthoxide fiber. OFC, paper PDP2.

Kazansky, P.; Russell, P. and Takabe, H. (1997). J. Lightwave Tech., Vol. 15, pp. 1484.

Lenz, G.; Zimmermann, J.; Katsufuji, T.; Lines, M.; Hwang, H.; Spalter, S.; Slusher, R.; Cheong, S.; Sanghera, J. and Aggarwal, I. (2000). Optics Letts., Vol. 25, pp. 254.

Lee, J.; Tanemura, T.; Kikuchi, K.; Nagashima, T.; Hasegawa, T.; Ohara, S. and Sugimoto, N. (2005). Experimental comparison of a Kerr nonlinearity figure of merit including the stimulated Brillouin scattering threshold for state-of-the-art nonlinear optical fibers. Opt. Lett. 30, 1698-1700.

Nasu, H.; Ibara, Y. and Kubodera, K. (1989). J. Non-Cryst. Solids, Vol. 110, pp. 229.

Ogusu, K. (2002). Analysis of Steady-State Cascaded Stimulated Brillouin Scattering in a Fiber Fabry-Pérot Resonator. IEEE Photon. Tech. Lett. 14, pp. 947-949.

Ogusu, K.; Li, H. and Kitao, M. (2004). Brillouin-gain coefficients of chalcogenide glasses. J. Opt. Soc. Am. B., 21, pp. 1302-1304.

Okawachi, Y.; Bigelow, M.; Sharping, J.; Zhu, Z.; Schweinsberg, A.; Gauthier, D.; Boyd, R. and Gaeta, A. (2005). Phys. Rev. Lett. 94, pp. 153902.

Pelusi, M; Ta'eed, V; Fu, L.; Magi, E.; Lamont, M; Madden, S; Choi, D; Bulla, D; LutherDavies, B; Eggleton, B; (2008) Applications of highly-nonlinear chalcogenide glasss devices tailored for high-speed all-optical signal processing, IEEE J. Sel. Top in Quant. Electron., 14, pp. 529-539.

Richardson, K.; McKinley, J.; Lawrence, B.; Joshi, S. and Villeneuve, A. (1998). Opt. Mats., Vol. 10, pp. 155.

Ruffin, A. (2004). Stimulated Brillouin Scattering: An overview of measurements, system impairments, and applications. NIST Symposium on Optical Fiber Measurements, Technical Digest, pp. 23-28.

Ruffin, A.; Li, M.; Chen, X.; Kobyakov, A. and Annunziata, F. (2005). Brillouin gain analysis for fibers with different refractive indices. Opt. Lett. 30, pp. 3123-3125.

Sanghera, J.; Busse, L. and Aggarwal, I. (1994a). J. Appl. Phys., Vol.75, pp. 4885 .

Sanghera, J.; Nguyen, V.; Pureza, P.; Kung, F.; Miklos, R. and Aggarwal, I. (1994b). J. Lightwave Tech., Vol. 12, pp. 737.

Sanghera, J.; Aggarwal, I.; Busse, L.; Pureza, P.; Nguyen, V.; Miklos, R.; Kung, F. and Mossadegh, R. (1995). SPIE, Vol.2396, pp. 71.

Sanghera, J.; Aggarwal, I.; Busse, L.; Pureza, P.; Nguyen, V.; Kung, F.; Shaw L. and Chenard, F. (2005). Chalcogenide Optical Fibers Target Mid-IR Applications. Laser Focus World, April Vol. 41 No. 4, pp. 83-87.

Shaw, L.; Thielen, P.; Kung, F.; Nguyen, V.; Sanghera, J. and Aggarwal, I. (2005). IR supercontinuum generation in As-Se photonic crystal fiber. Proceedings of Advanced Solid State Photonics, TOPS vol. 98, Optical Society of America. 
Slusher, R.; Hodelin, J.; Sanghera, J.; Shaw, L. and Aggarwal, I. (2004). JOSA-B, Vol. 21, pp. 1146.

Song, K.; Herráez, M. and Thévenaz, L. (2005). Observation of pulse delaying and advancement in optical fibers using stimulated Brillouin scattering. Opt. Expr. 13, pp. 82-88.

Song, K.; Abedin, K.; Hotate, K.; Herráez, M. and Thévenaz, L. (2006). Highly efficient Brillouin slow and fast light using $\mathrm{As}_{2} \mathrm{Se}_{3}$ chalcogenide fiber. Opt. Expr. 14, pp. 5860-5865.

Thielen, P.; Shaw, L.; Pureza, P.; Nguyen, V.; Sanghera, J. and Aggarwal, I. (2003a). Smallcore As-Se fiber for Raman amplification. Optics Letters, 28, pp. 1406-1408.

Thielen, P.; Shaw, L.; Sanghera, J. and Aggarwal, I. (2003b). Optics Express, Vol. 11, pp. 32483253. 


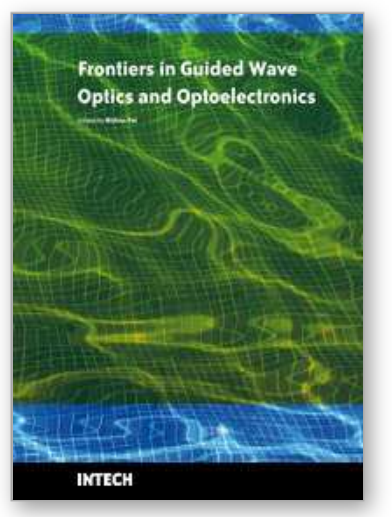

\author{
Frontiers in Guided Wave Optics and Optoelectronics \\ Edited by Bishnu Pal
}

ISBN 978-953-7619-82-4

Hard cover, 674 pages

Publisher InTech

Published online 01, February, 2010

Published in print edition February, 2010

As the editor, I feel extremely happy to present to the readers such a rich collection of chapters authored/coauthored by a large number of experts from around the world covering the broad field of guided wave optics and optoelectronics. Most of the chapters are state-of-the-art on respective topics or areas that are emerging. Several authors narrated technological challenges in a lucid manner, which was possible because of individual expertise of the authors in their own subject specialties. I have no doubt that this book will be useful to graduate students, teachers, researchers, and practicing engineers and technologists and that they would love to have it on their book shelves for ready reference at any time.

\title{
How to reference
}

In order to correctly reference this scholarly work, feel free to copy and paste the following:

Jas S. Sanghera, L. Brandon Shaw, C. M. Florea, P. Pureza, V. Q. Nguyen, F. Kung, Dan Gibson and I. D. Aggarwal (2010). Nonlinear Properties of Chalcogenide Glass Fibers, Frontiers in Guided Wave Optics and Optoelectronics, Bishnu Pal (Ed.), ISBN: 978-953-7619-82-4, InTech, Available from:

http://www.intechopen.com/books/frontiers-in-guided-wave-optics-and-optoelectronics/nonlinear-properties-ofchalcogenide-glass-fibers

\section{INTECH}

open science | open minds

\section{InTech Europe}

University Campus STeP Ri

Slavka Krautzeka 83/A

51000 Rijeka, Croatia

Phone: +385 (51) 770447

Fax: +385 (51) 686166

www.intechopen.com

\section{InTech China}

Unit 405, Office Block, Hotel Equatorial Shanghai

No.65, Yan An Road (West), Shanghai, 200040, China

中国上海市延安西路65号上海国际贵都大饭店办公楼 405 单元

Phone: +86-21-62489820

Fax: +86-21-62489821 
(C) 2010 The Author(s). Licensee IntechOpen. This chapter is distributed under the terms of the Creative Commons Attribution-NonCommercialShareAlike-3.0 License, which permits use, distribution and reproduction for non-commercial purposes, provided the original is properly cited and derivative works building on this content are distributed under the same license. 